\title{
Uma Proposta para o Ensino de Química Através \\ da Abordagem CTSA: Uma Sequência Didática
}

\author{
para a Temática Água
}

Edson de Oliveira Costa* (Graduando em Química na Universidade Federal de Campina - UFCG)

J osé Carlos Oliveira Santos (Professor da UABQ/CES na Universidade Federal de Campina Grande -

UFCG)

*E-mail: edsoncosta38@yahoo.com.br

Resumo: A abordagem de ensino através do movimento Ciência, Tecnologia, Sociedade e Ambiente (CTSA) está vinculada à educação científica e ambiental e tem como objetivo promover um pensamento crítico e consciente sobre os aspectos que vêm ocorrendo pelo mundo. No que tange a Química, o seu ensino passa de uma fase de apresentação da ciência como neutra para uma visão interdisciplinar, em que o contexto da pesquisa científica e suas consequências sociais. Este trabalho tem por objetivo desenvolver uma sequência didática com uma abordagem CTSA com o uso da temática água para desenvolver o conhecimento químico no ensino médio. Ficou evidenciado através do desenvolvimento das atividades deste trabalho que os alunos envolvidos tiveram um melhor desempenho com conteúdos estudados. Trabalhar com enfoques inovadores é importante para o desenvolvimento de uma prática inovadora no ensino de química. Os resultados demonstraram que através de uma educação usando CTSA foi possível criar condições para que os alunos desenvolvessem habilidades e competências, tornando-os capazes de discutir questões científicas e tecnológicas que permeiam a sociedade.

Palavras-chave: Ensino de química; CTSA; água; sequência didática; interdisciplinaridade.

Espaço reservado para organização do congresso. 


\section{I ntrodução}

A abordagem de ensino Ciência, Tecnologia, Sociedade e Ambiente (CTSA) está vinculada à educação científica e ambiental, entretanto o movimento ciência CTSA, tem como objetivo promover um pensamento crítico e consciente sobre os aspectos que vêm ocorrendo pelo mundo. Uma prática pedagógica baseada na utilização de fatos do dia-a-dia para ensinar conteúdos científicos pode caracterizar o cotidiano em um papel secundário, ou seja, este servindo como mera exemplificação ou ilustração para ensinar conhecimentos químicos (WARTHA et al., 2013). Com isso, o ensino de ciências passa de uma fase de apresentação da ciência como neutra para uma visão interdisciplinar, em que o contexto da pesquisa científica e suas consequências sociais, político e culturais são elementos marcantes (KRASILCHIK e MARANDINO, 2007).

Nesse estudo a perspectiva CTS (Ciência Tecnologia Sociedade) ou CTSA (Ciência Tecnologia Sociedade e Ambiente) como uma abordagem no ensino de Química, visa preparar os alunos para o exercício da cidadania e caracterizam-se por uma abordagem dos conteúdos científicos no seu contexto social. Segundo Praia et al. (2007), as relações CTSA marcam o desenvolvimento científico, com destaque para as repercussões de todo tipo de conhecimentos científicos e tecnológicos (desde a contribuição da ciência e da técnica para o desenvolvimento da humanidade até aos graves problemas que hipotecam o seu futuro), permitindo a preparação para a cidadania na tomada de decisões.

O papel da escola, que é indispensável, deve instrumentalizar os docentes sobre conhecimentos científicos, mas como afirmam Krasilchik e Marandino (2007) nem ela nem nenhuma instituição sozinha têm condições de proporcionar e acompanhar a evolução de todas as informações científicas necessárias para a compreensão do mundo. Alfabetizar, portanto, os cidadãos em ciência e tecnologia é hoje uma necessidade do mundo contemporâneo (SANTOS e SCHNETZLER, 1997). Não se trata de mostrar as maravilhas da ciência, como a mídia já o faz, mas de disponibilizar as representações que permitam ao cidadão agir, tomar decisão e compreender o que está em jogo no discurso dos especialistas (FOUREZ, 1995).

Os Parâmetros Curriculares Nacionais, PCNEM, (BRASIL, 2002) destacam a importância do ensino de ciências e, especificamente do ensino de Química, para formação do cidadão. Portanto entende-se que o aprendizado proporciona aos alunos uma compreensão das transformações químicas que ocorrem no mundo físico de forma abrangente e integrada e assim possam julgar com propriedade as informações acontecidas da tradição cultural, da mídia e da própria escola e tomar decisões autonomamente, enquanto cidadãos. Reconhece-se que o ensino de ciências e, especificamente o ensino de Química, com enfoque CTSA, requer uma postura diferenciada do professor que segundo Pinheiro et al (2007) é o grande articulador para garantir a mobilização dos saberes, o desenvolvimento do processo e a realização de projetos.

Considera-se que o uso da temática "água" para desenvolver o conhecimento químico no Ensino Médio permite a inclusão de um número maior de conceitos, dependendo da disponibilidade de tempo. Ainda mais, a proximidade dos problemas ambientais da vida do aluno é característica que favorece o trabalho no que diz respeito à formação do educando enquanto cidadão que interage com o mundo e é capaz de transformar seu entorno (GOUVEIA, 2009), pois temos hoje a nossa disposição a possibilidade de acessar embasamentos inerentes a conhecimentos científicos e tecnológicos que permitem uma sustentação inicial, sobre importantes preocupações de natureza sócia, ambiental, como sustentabilidade ambiental e ética (ALVES et al., 2007).

Pinheiro (2007), afirma que há necessidade do enfoque CTSA ser introduzido já no ensino fundamental, a fim de formar um cidadão que tenha sua atenção despertada para os aspectos que envolvem o contexto científico tecnológico e social. É importante no ensino de química uma abordagem CTSA que transmita ao aluno uma visão social e ambiental do meio que está, quando se faz uma aula com esse enforque, os mesmos tem um interesse por aprender os conteúdos que estão sendo estudados, pois busca foca a realidade ambiental e social de cada indevido.

Com objetivo principal da educação numa abordagem CTSA é o de possibilitar o conhecimento científico para os estudantes, auxiliando-os a construir conhecimentos, habilidades e valores necessários para tomar decisões responsáveis sobre questões de ciência e tecnologia na sociedade e atuar na solução de tais questões (SANTOS e MORTIMER, 2002). A escolha de um tema para trabalhar os conceitos científicos da química é importante, pois deve abranger a realidade dos 
alunos. Este trabalho tem por objetivo desenvolver uma sequência didática com uma abordagem CTSA com o uso da temática água.

\section{Metodologia}

A pesquisa foi realizada com 40 alunos do $2^{\circ}$ ano do ensino médio regular da Escola Estadual Orlando Venâncio dos Santos situada na cidade de Cuité- PB. A sequência didática foi construída a partir de discussões sobre a abordagem CTSA no ensino de Química. Inicialmente foi destacado o significado do ensino de Química com o enfoque CTSA, a ruptura com as visões simplistas das relações entre ciência, tecnologia e sociedade e os aspectos metodológicos dessa orientação, a partir das discussões foi escolhido o tema água. Por ser uma substância de grande reciclagem e um bem em abundância no planeta, que está sendo desperdiçado, buscou-se aproximar os conceitos químicos através de uma abordagem CTSA.

Dentro desta perspectiva CTSA, a proposta educacional metodológica deslocou o foco principal do conteúdo para uma abordagem que deu ao estudante certa autonomia para se posicionar frente aos conflitos sociais que virão, quando das diferentes aplicações científico-tecnológicas (PENHA et al., 2009). Foi desenvolvida uma proposta de uma sequência didática, relacionada ao tema proposto água, constituída por três momentos: O primeiro momento consistiu no contato com os sujeitos da pesquisa, através de um questionário qualitativo com o intuito de investigar a opinião dos alunos em relação ao tema proposto para se analisar os conhecimentos prévios com as seguintes perguntas, 1) Como podemos contribuir com a utilização da água de forma responsável? 2) É possível afirmar que visualmente a água é própria para consumo? 3) Existe diferença entre água pura e água potável?

No segundo momento aconteceu à exposição do vídeo: "Matéria de Capa - Água, escassez e soluções". Após a exposição do vídeo foi proposto um debate com enfoque CTSA com a turma, que foi dividida em grupos para uma melhor socialização do conhecimento. No terceiro momento, ocorreu uma aula mostrando as principais fontes de água disponíveis na cidade, onde levantou questionamentos do tema pelos alunos. Nesta aula introduziram-se conteúdos como, por exemplo, conceitos de ligação química, partindo dos íons presentes no solo e do equilíbrio desses íons. Uma introdução à ligação iônica foi feita ao ser trabalhado os íons presentes na água doce e na água salgada. O tema pode ser aprofundado, juntamente com os outros tipos de ligações, presentes nas moléculas de $\mathrm{H}_{2} \mathrm{O}$ e nas de $\mathrm{N}_{2}$.

\section{Resultados e Discussão}

De acordo com Zabala (1998), sequências didáticas é um conjunto de atividades ordenadas, estruturadas e articuladas para a realização de certos objetivos educacionais, que têm um princípio e um fim conhecidos tanto pelos professores como pelos alunos. A sequência didática foi construída para uma turma da $2^{\mathrm{a}}$ série do ensino médio, sendo utilizado um total de três aulas de 50 minutos cada, sobre o conteúdo de introdução a ligação iônica, tipos de ligações e moléculas.

Iniciou-se através da aplicação de um questionário qualitativo, onde foi possível analisar os conhecimentos prévios dos alunos sobre o tema proposto. Para o desenvolvimento da pesquisa, realizou-se um diagnóstico das concepções prévias dos sujeitos em relação à abordagem CTSA.

No questionário aplicado foram feitas três perguntas. A primeira pergunta dizia: Como podemos contribuir com a utilização da água de forma responsável?. Cujas respostas estão na Figura 1. 
Figura 1 - Respostas dos estudantes a pergunta: Como podemos contribuir com a utilização da água de forma responsável?

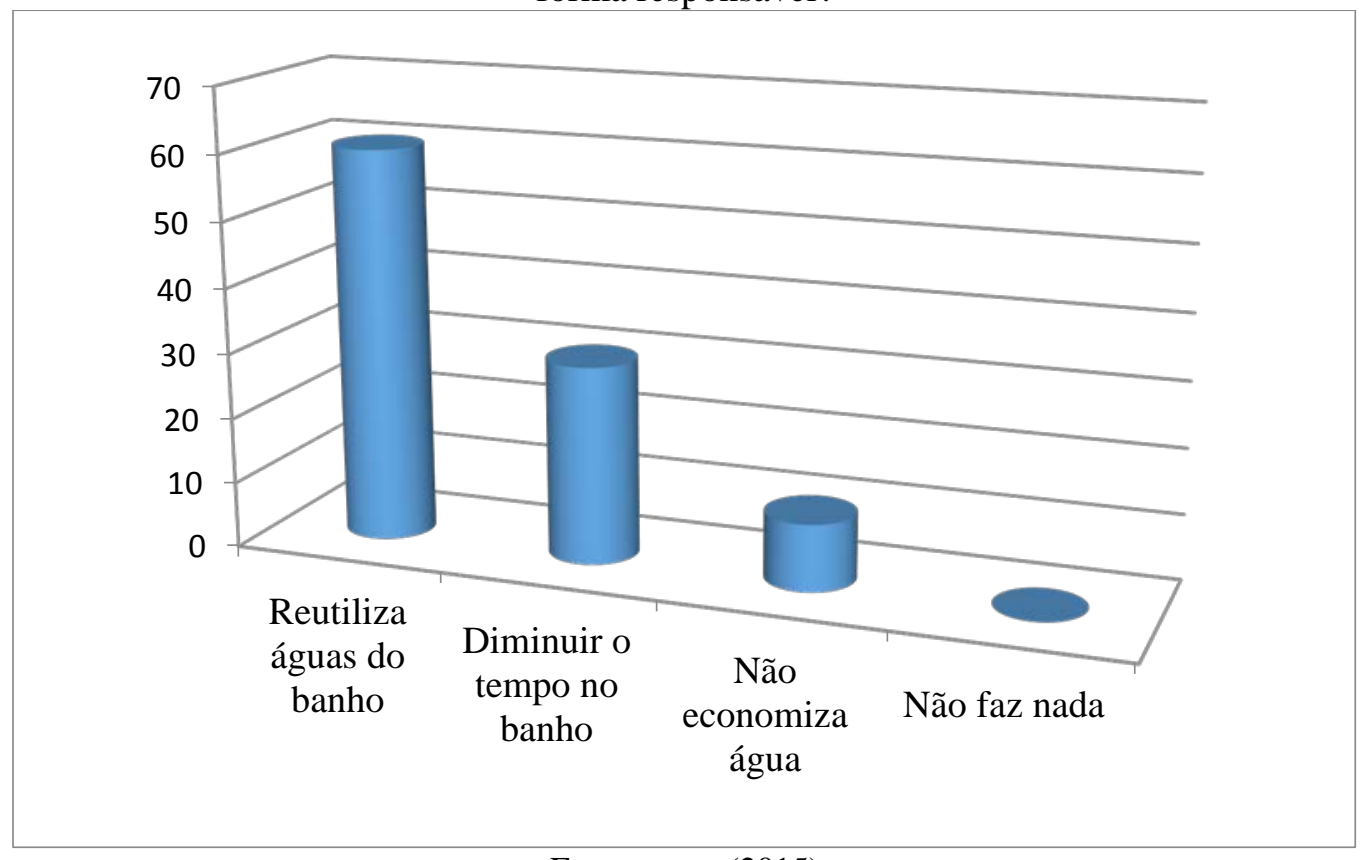

Fonte: autor (2015)

De acordo com a Figura 1, observou que 95\% das respostas estão corretas, ou seja, os alunos responderam que para a utilização da água de forma racional deve-se evitar o desperdício da água, como por exemplo, diminuindo o tempo no banho e reutilizando a água do banho.

Na questão 2, 40,05 \% dos alunos responderam que não é possível saber se a água é própria para o consumo ou não só visualizando. Por outro lado, 59,95\% afirmaram que é possível saber se a água está própria para consumo só visualizando se a mesma esta límpida. Com isso acredita-se que os conhecimentos prévios da turma estão confusos em relação à pergunta (Figura 2).

Figura 2 - Respostas dos estudantes a pergunta: É possível afirmar que visualmente a água é própria para consumo?

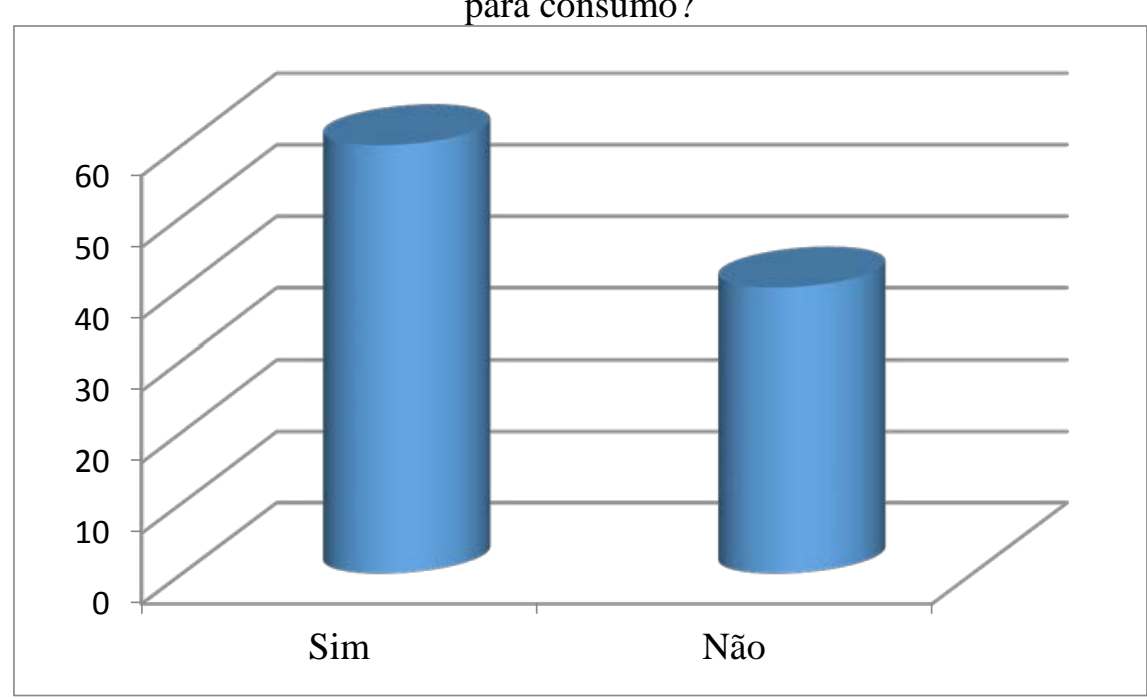

Fonte: autor (2015)

Na questão 3, 93,75\% dos alunos afirmaram que existe diferença entre água pura e água potável e 6,25\% afirmaram que não existe diferença. Assim os alunos investigados responderam as perguntas de forma satisfatória (Figura 3). 
Figura 3 - Respostas dos estudantes a pergunta: Existe diferença entre água pura e água potável?

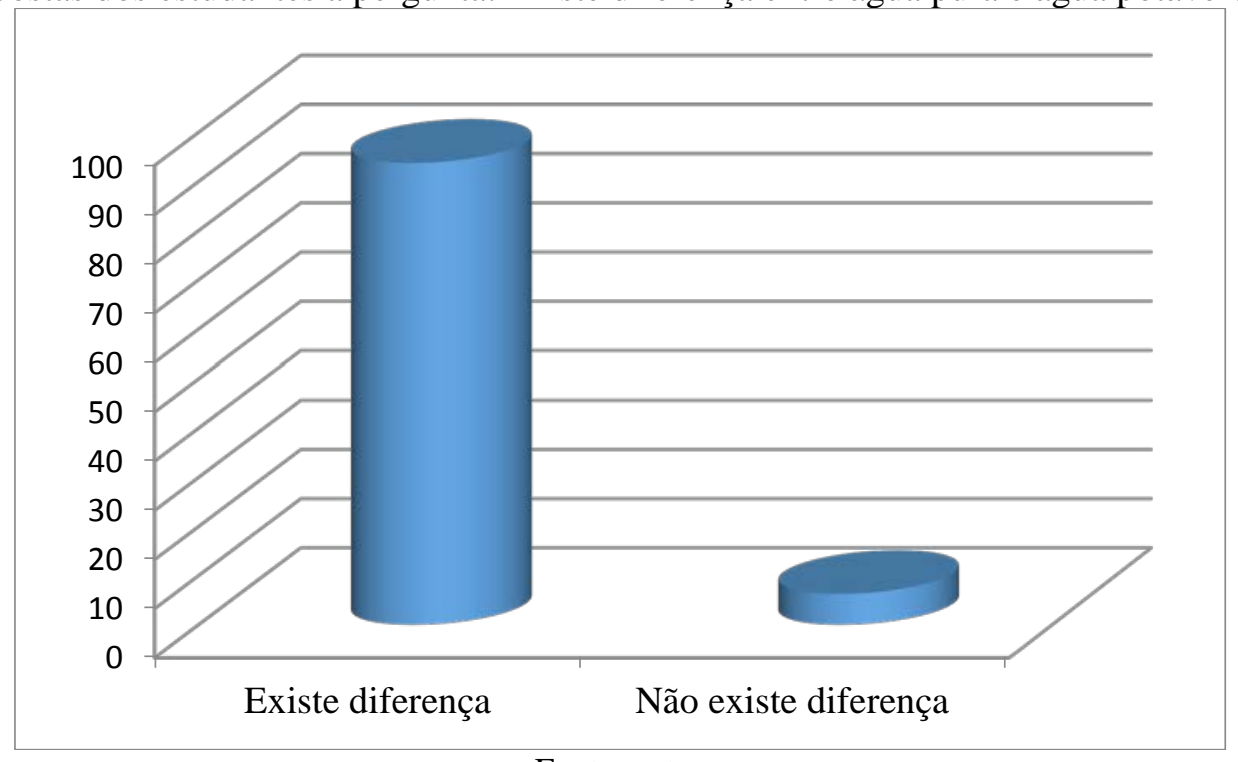

Fonte: autor

No segundo momento aconteceu a exposição do vídeo: "Matéria de Capa - Água, escassez e soluções”, sendo desejável que o professor esteja preparado para utilizar a linguagem audiovisual com sensibilidade e senso crítico de forma a desenvolver, com seus alunos, uma alfabetização audiovisual (MANDARINO, 2002). Após a exposição do vídeo realizou-se um debate com enfoque CTSA. Após o levantamento das opiniões foi proposto uma discussão com os grupos sobre as questões trazidos pelos problemas ambientais enfrentados na região. Os discentes discutiram sobre a situação da crise hídrica na região e os efeitos da seca para o homem do campo.

Os grupos elaboram uma síntese sobre os temas propostos visualizados no vídeo, e cada grupo foi representado por um membro para expor suas ideias. Explorou-se com muita ênfase as discussões a fim de que os alunos percebessem que a escassez de água na região é um problema enfrentado pela população e, que os mesmos estão inseridos no contexto, ou seja, é uma situação enfrentada por todos.

No terceiro momento, foi desenvolvida uma aula mostrando as principais fontes de água disponíveis na cidade, onde levantou-se questionamentos pelos alunos acerca do tema. Nesta aula introduziu-se conteúdos como, por exemplo, conceitos de ligação química, partindo dos íons presentes no solo e do equilíbrio desses íons. Uma introdução à ligação iônica foi feita ao trabalhar os íons presentes na água doce e na água salgada, aprofundou-se para os outros tipos de ligação, presentes nas moléculas de $\mathrm{H}_{2} \mathrm{O}$ e nas de $\mathrm{N}_{2}$.

Por fim realizou-se uma discussão sobre as aulas vivenciadas durante o desenvolvimento da sequência didática. Contudo, considera-se que esse ensino voltado para a cidadania, tecnologia, sociedade e ambiente, é possível para ensino de química desde que o professor procure se atualizar e utilizar as tecnologias para fins de melhorar a qualidade do ensino nas escolas públicas nesta nova abordagem.

\section{Conclusões}

Ficou evidente neste trabalho que a utilização de enfoques inovadores são fatores de destaque no processo de ensino e aprendizagem e, em particular, no funcionamento da educação CTSA. Com o desenvolvimento desta sequência, evidenciou-se o desenvolvimento dos alunos envolvidos em discutir os problemas sociais e ao mesmo tempo aprender conteúdos químicos, incorporando-os ao seu cotidiano, vivenciando a realidade de sua região e sendo sujeitos ativos na construção de uma sociedade melhor.

De acordo com os resultados, percebe-se que os alunos envolvidos tiveram um melhor desempenho quando os conteúdos estudados foram focados pelo modelo CTSA. Ficou claro que trabalhar com enfoques inovadores é importante para o desenvolvimento de uma prática pedagógica eficaz no ensino de química. Nesse sentido, é importante realizar ações concretas, como as atividades realizadas neste trabalho, para conhecer as concepções prévias dos discentes e fornecer lhes teorias e 
estratégias para uma aprendizagem contextualizada na abordagem CTSA, na construção e reconstrução de saberes e formação do cidadão crítico e participativo.

A Proposal for Chemistry Teaching Through the CTSA approach: a Teaching Sequence for the Thematic Water

Albstract: The teaching approach through the Science, Technology, Society and Environment movement (CTSA) is linked to scientific and environmental education and aims to promote a critical and conscious thought on aspects that are taking place around the world. When it comes to chemistry, his teaching is but a stage presentation of science as neutral for an interdisciplinary view, in the context of scientific research and its social consequences. This work aims to develop a didactic sequence with a CTSA approach using the water theme to develop chemical knowledge in high school. Evidenced by developing the activities of this work that the students involved have performed better with contents studied. Working with innovative approaches is important for the development of an innovative practice in teaching chemistry. The results showed that through education using CTSA was possible to create conditions for students to develop skills and expertise, making them able to discuss scientific and technological issues that permeate society.

Keywords: Chemistry education; CTSA; water; didactic sequence; interdisciplinarity.

\section{Referências bibliográficas}

ALVES, J. A. P.; MION, R. A.; CARVALHO, W. L. P. Implicações da relação Ciência-TecnologiaSociedade-Ambiente na formação de professores de Física. In: Anais do SI MPÓSI O NACI ONAL EM ENSI NO DE Fí SI CA. São Luís: CEFET, 2007.

BRASIL. Ministério da Educação - MEC, Secretaria de Educação Média e Tecnológica - Semtec. PCN + Ensino Médio: orientações educacionais complementares aos Parâmetros Curriculares Nacionais- Ciências da Natureza, Matemática e suas Tecnologias. Brasília: MEC, 2002.

GOUVEIA, R. C. Possibilidades Pedagógicas da Física no Meio Ambiente. São Paulo: Revista I luminart, v.1, n. 1, 2009.

KRASI LCHIK, M. e MARANDINO, M. Ensino de ciências e cidadania. 2a ed. São Paulo: Moderna, 2007.

MANDARINO, M.C.F. Organizando o trabalho com vídeo em sala de aula. Morpheus - Revista Eletrônica em Ciências Humanas. v. 1, n. 1, 2002.

PINHEI RO, N. A. M.; MATOS, E. A. S. A.; BAZZO, W. A., Refletindo acerca da ciência, tecnologia e sociedade: enfocando o ensino médio. Revista I beroamericana de Educação. n. 44, 2007.

SANTOS, W. L. P.; MORTIMER, E. F., Uma análise de pressupostos teóricos da abordagem CTS no contexto da educação brasileira. Ensaio: Pesquisa em Educação em Ciências, v. 2, n. 2, 2002.

FOUREZ, G. A construção das ciências: introdução à filosofia e à ética das ciências. São Paulo: Editora da Universidade Estadual Paulista, 1995.

PENHA, P. S.; MORAES, B. R.; VIANNA, M. D. Uma Sequência Didática para Estudo do Eletromagnetismo com uma Abordagem CTS. Anais do Simpósio Nacional de Ensino de Física. INTERFACES, 2009.

ZABALA, A. A prática educativa: como ensinar. Porto Alegre: Artes Médicas Sul Ltda., 1998. 